\title{
Sperm motility in European hake, Merluccius merluccius, and characterization of its spermatozoa concentration and volume, spermatocrit, osmolality and $\mathrm{pH}$
}

\author{
Anne-Laure Groison ${ }^{\mathrm{a}, \mathrm{b},{ }^{*}}$, Marc Suquet ${ }^{\mathrm{c}}$, Jacky Cosson $^{\mathrm{d}}$, Ian Mayer ${ }^{\mathrm{a}, \mathrm{g}}{ }^{\mathrm{g}}$, Armelle Severe ${ }^{\mathrm{e}}$, Jean-Marie \\ Bouquet ${ }^{f}$, Audrey J. Geffen ${ }^{\mathrm{a}}$, Anne Christine Utne-Palm ${ }^{\mathrm{a}}$ and Olav Sigurd Kjesbu ${ }^{\mathrm{b}}$
}

\footnotetext{
a Department of Biology, University of Bergen, P.O. Box 7803, Thormøhlensgate 55, N-5020 Bergen, Norway

${ }^{b}$ Institute of Marine Research, Nordnesgaten 50, P.O. Box 1870 Nordnes, N-5817 Bergen, Norway

c IFREMER, PFOM/ARN, 29840 Argenton, France

d UMR 7009, CNRS, University P \& M Curie Marine Station, 06230 Villefranche-sur-Mer Cedex, France

e PFOM/ARN IFREMER Centre de Brest BP 70, 29280 Plouzané, France

${ }^{f}$ Sars International Centre for Marine Molecular Biology, Thormøhlensgate 55, N-5008 Bergen, Norway

${ }^{g}$ Norwegian School of Veterinary Science, N-0033 Oslo, Norway
}

*: Corresponding author : A.-L. Groison, Tel.: + 47 55236350; fax: + 47 55238555, email address : annelaure.groison@imr.no

\begin{abstract}
:
Due to stock declines there is a growing interest in farming of European hake Merluccius merluccius. Thus, knowledge of its sperm biology is of importance not only for purposes of broodstock management, but also for the development of sperm preservation techniques. Hake sperm were collected from mature males caught during the summer-early autumn waters off western Norway and during the winter-early spring in the Bay of Biscay (France). Sperm quality characteristics were assessed after storage at $4{ }^{\circ} \mathrm{C}$ for $25 \pm 14 \mathrm{~h}$. Average $( \pm \mathrm{SD}$ ) values for Norwegian and French samples respectively were (i) sperm volume: $3.9 \pm 4.0$ and $2.6 \pm 4.0 \mathrm{ml}$; (ii) spermatozoa concentration: $6.6 \pm 3.2$ and $13.9 \pm 5.1 \times 10^{9}$ spermatozoa/ml; (iii) spermatocrit: $80.2 \pm 3.3$ and $81.8 \pm 10.7 \%$; and (iv) total number of spermatozoa: $23.5 \pm 30.0$ and $35.1 \pm 36.2 \times 10^{9}$. Average osmolality and $\mathrm{pH}( \pm \mathrm{SD})$ of French samples were $349 \pm 28 \mathrm{mOsmol} / \mathrm{kg}$ and $7.6 \pm 0.1$, respectively. Activation by transfer into full sea water $(100 \mathrm{SW})$ or $10 \%$ ovarian fluid in sea water (10 OF) occurred synchronously for virtually all spermatozoa and the percent sperm motile decreased with post activation time. When transferred into $50 \%$ sea water diluted with distilled water (50 SW) only a few spermatozoa were activated initially but subsequently reached a maximum percentage of motility followed by a decline. Hake sperm motility declined rapidly to $50 \%$ of motility $70 \mathrm{~s}$ after activation with $100 \mathrm{SW}$. Sperm were motile for longer when activated with $50 \mathrm{SW}(1570 \pm 295 \mathrm{~s})$ or 10 OF (718 $\pm 71 \mathrm{~s})$ compared to $100 \mathrm{SW}(317 \pm 121 \mathrm{~s})$. Undiluted hake sperm stored at $4{ }^{\circ} \mathrm{C}$ up to 10 days retained $10 \%$ motility when activated with $100 \mathrm{SW}$. When cryopreserved, the motility recovery index of the cells at thawing ranged from 0 to $76.4 \%$. These results describe for the first time the sperm traits of European hake following successful cryopreservation, and also show the importance of activation medium on sperm motility.
\end{abstract}

Keywords: Cryopreservation; Merluccius merluccius; Osmolality; pH; Sperm motility; Spermatocrit 
48 Key-words: Cryopreservation, Merluccius merluccius, osmolality, pH, sperm motility, spermatocrit.

\section{Introduction}

The reproductive biology of European hake (Merluccius merluccius) has been studied extensively in the field, but mainly in the context of fecundity regulation and fisheries analysis, and concentrating primarily on females (Murua and Motos, 2006). European hake is a highly important commercial species throughout its geographical range, especially in Spain and Italy.

Because European hake catches have been decreasing since the 1960's (FAO, 2006), the commercial viability of aquaculture production and the interest in hake as a potential aquaculture species has recently increased (Quémener et al., 2002; Kjesbu et al., 2006). Some researchers have stated that the hake is one of the most promising new species for marine aquaculture (Engelsen et al., 2004). Quémener et al. (2002) highlighted its fast growth rate as factor contributing to the high potential value for aquaculture, as well as its excellent flesh quality which gives it a very high market value when sold fresh.

For successful domestication of hake, a better understanding of its reproductive biology, including sperm biology, is needed for purposes of broodstock management and also for the development of sperm storage techniques, including cryopreservation. Such information is presently lacking, except for spermatozoa ultrastructure which was studied by Medina et al. (2003), and spermatozoa motility characteristics studied by Cosson et al. (2008a). Male reproductive biology has not received much attention primarily because hake is sensitive to handling, difficult to keep alive after capture 
72 (Hickling, 1933; Belloc, 1935), and therefore has only rarely been kept in captivity

73 (Bjelland and Skiftesvik, 2006). To date, only two captive broodstocks have been

74 established, the oldest is in Brekke, Norway (R. Salte, Norwegian University of Life

75 Sciences, pers. comm.), and a more recent one in Vigo, Spain (F.J. Sanchez, Instituto

76 Español de Oceanografia, Vigo, Spain, pers. comm.).

77 Male fertilization potential is dependent on sperm quality (Trippel, 2003). The most common factors employed in studying sperm biology are the structure and motility parameters of the spermatozoa, the biochemistry of the spermatozoa and seminal plasma, and the metabolism of spermatozoa (respiration and energetics of motility)

81 (Billard and Cosson, 1992; Billard et al., 1995). The sensitivity of sperm to storage and cryopreservation is important information for broodstock management programs. This can be assessed by studying the activation, motility, and fertility of stored sperm (Billard and Cosson, 1992; Billard et al., 1995).

The peak spawning time of hake is in March in waters south of the Bay of Biscay (France), and occurs progressively later at higher latitudes (Casey and Pereiro, 1995). The spawning time along the west coast of Norway is expected to occur during late summer; Kvenseth et al. (1996) showed records of ripening hake in August in these waters. Male hake from both the northern (Norway) and middle (Bay of Biscay) sections of their geographic range were collected as these regions are located in

91 proximity to aquaculture research facilities and the associated industry.

In the present study, sperm production characteristics (volume, spermatozoa concentration, spermatocrit and total number of spermatozoa), biochemistry of the total sperm (osmolality and $\mathrm{pH}$ ), motility characteristics of the spermatozoa after activation including survival after storage at $4^{\circ} \mathrm{C}$ and freezability for cryopreservation were studied 96 in European hake. Collecting sperm from mature males from the same area in different 
97 time periods would in the future be of interest to evaluate seasonal changes in sperm 98 quality.

100 2. Materials and methods

101 2.1. Fish and sperm collection

102 Adult wild European hake were sampled during the spawning season from two 103 geographically separated Atlantic populations, one from Western Norway $\left(61^{\circ} 34^{\prime} \mathrm{N}, 5^{\circ}\right.$ $\left.10456^{\prime} \mathrm{E}\right)$, and the other from the Bay of Biscay, France $\left(47^{\circ} 44^{\prime} \mathrm{N}, 4^{\circ} 2^{\prime} \mathrm{W}\right)$. Fish were 105 caught by gillnets (13.5 cm mesh size) set overnight at depths of between $30-180 \mathrm{~m}$ 106 over sandy sea bottom. Each morning sperm were collected from live or recently dead 107 fish (few hours) which were retrieved from the gillnets. Less than $10 \%$ of the mature 108 males were discarded according to these criteria. Sperm were collected from 19 sexually 109 mature males from mid-August until mid-October in 2005 and 2006 off Western

110 Norway (main spawning season for Norwegian hake) and from 45 sexually mature 111 males from March to early April in 2006 and 2007 in the Bay of Biscay (end of 112 spawning season for French hake). Sperm were manually stripped: the fish genital pore 113 was rinsed with fresh water and dried quickly off before sperm were collected in 114 graduated syringes. Special care was taken to collect all the available sperm from each 115 fish and not to contaminate the sperm sample with blood, urine or seawater. Any 116 potentially contaminated sperm samples were discarded. Syringes were stored in

117 individual labeled sealed plastic bags to avoid cross-contamination and samples were 118 stored in a polystyrene rack above crushed ice which filled the bottom of a closed 119 polystyrene box. The ice was changed approximately every $6 \mathrm{~h}$ to maintain a constant 120 temperature of $4^{\circ} \mathrm{C}$ until the samples were brought back to the laboratories within 7 to $12149 \mathrm{~h}$ post gamete collection. 
124 Stripped fish (61 out of 64 collected) were transported to the laboratories to be dissected 125 within 10 to $52 \mathrm{~h}$ of sampling. There, fish were measured for total length (TL in $\mathrm{cm}$ ), 126 total weight (TW in g), gonadosomatic index (GSI in \%), hepatosomatic index (HSI in $127 \%$ ) and condition factor $(\mathrm{K})$. The following formulas were used to calculate these 128 variables:

\subsection{Sperm production indices}

Total sperm volume was estimated with $0.1 \mathrm{ml}$ precision. Spermatozoa concentration was estimated by counting spermatozoa in a Fuchs-Rosenthal chamber

136 (Glaswarenfabrik Karl Hecht GmbH\&Co, Hecht Assist, Sondheim, Germany) or in a

137 Malassez chamber (Preciss, Strasbourg, France) at $400 \mathrm{X}$ magnification. Samples were diluted from 1:500 to $1: 1000$, depending on sperm concentration, in a non-activating medium (NAM) described for sea bass (Dicentrarchus labrax) sperm (Fauvel et al., 1998). After several minutes to allow sedimentation of cells, heads were counted.

141 Sperm counts were duplicated using separate subsamples, and spermatozoa

142 concentrations estimated based on the average of the counts. Spermatozoa concentration

143 was expressed as the number of spermatozoa per $\mathrm{ml}$ of sperm. The total number of

144 spermatozoa for each male was estimated from the total sperm volume multiplied by the

145 spermatozoa concentration. Spermatocrit values were measured by collecting duplicate

146 subsamples of freshly stripped sperm in $75 \mathrm{~mm}$ heparinized capillary tubes (KEBO 
147 Laboratories AB, Stockholm, Sweden). After proper sealing, the samples were spun for

1485 minutes at $10.000 \mathrm{rpm}(250 \mathrm{~g})$ in a Hettich Haematocrit centrifuge (Andreas Hettich

$149 \mathrm{GmbH} \&$ Co., Tuttingen, Germany). The spermatocrit value was calculated as the

150 percentage of spermatozoa volume relative to total sperm volume. Osmotic pressure

151 (mOsmol $/ \mathrm{kg}$ ) and $\mathrm{pH}$ of the total sperm were measured respectively using an

152 Advanced Micro Osmometer (13/13DR-Autocal, Hermann Roebling MESSTECHNIK,

153 Berlin, Germany) and a pH-meter (Minisis 8000, Tacussel Electronic, Villeurbanne,

154 France) with a micro-electrode (XC 161, Radiometer Analytical, Copenhagen, 155 Denmark).

\subsection{Measurement of sperm motility characteristics}

Sperm motility was evaluated by the same reader on every collected sample as

soon as they were transported to the laboratories which were set up with similar

160 conditions in both locations and equipped with the same material. Norwegian sperm

161 (Nw-sperm) motility was first evaluated within $18 \pm 8 \mathrm{~h}$ (mean $\pm \mathrm{SD}$ ) after gamete

162 collection and French (Fr) within $22 \pm 13 \mathrm{~h}$. Sperm motility was assessed using a two

163 step dilution procedure. Undiluted sperm as collected from sperm ducts were diluted

164 with NAM (dilution 1:20). No movement of sperm was observed and $0.3 \mu 1$ of this

165 diluted sperm were added to a $20 \mu \mathrm{m}$-depth Leja sperm counting chamber (Leja

166 Products BV, Nieuw-Vennep, the Netherlands) followed by $4.5 \mu \mathrm{l}$ of the activating-

167 medium (AM see below). Sperm and diluents were kept in the polystyrene box as

168 described above with the bottom filled with crushed ice $\left(4^{\circ} \mathrm{C}\right)$ when preparing the

169 mixture. The different AMs tested were: $100 \%$ filtrated sea water $(100 \mathrm{SW})$ (filter and

170 UV filter, Unik filtersystem AS, Os, Norway), $50 \%$ filtrated sea water diluted with

171 distilled water (50 SW), and $10 \%$ ovarian fluid diluted with SW (10 OF). The 
172 respective osmolalities $(\mathrm{mOsmol} / \mathrm{kg}$ ) of these three different AMs, measured using an

173 Advanced Micro Osmometer (13/13DR-Autocal, Hermann Roebling MESSTECHNIK,

174 Berlin, Germany), were: 998, 498 and 936 respectively. Bovine Serum Albumin (BSA

$1750.1 \%$, Sigma -Aldrich Inc., Sigma ref A9647, St-Louis, MO 63103 USA) was added to

176 both the NAM and AM to prevent spermatozoa sticking to glass surfaces (Cosson et al.,

177 2003). Following sperm activation at room temperature in both locations $\left(22^{\circ} \mathrm{C}\right)$, video

178 recordings were made using a Sony CCD black and white camera, mounted on an

179 Olympus negative-phase contrast microscope $200 \mathrm{X}$, linked to a video monitor. By

180 simple visual observation of the video recordings, the same trained reader throughout

181 the study estimated the percent sperm motile every $15 \mathrm{~s}$ after activation until all

182 spermatozoa ceased activity (in replicates for each sperm sample tested). Efficient

183 mixing was obtained within $5 \mathrm{~s}$ and therefore, video-recordings and percent sperm

184 motile observations started with a 5-10 s lag phase. Vibrating or stationary spermatozoa

185 (non progressive) were considered as non-motile. The total motility duration was

186 defined as the time from the activation until $10 \%$ of spermatozoa were still motile.

187 Changes in the percent sperm motile as a function of time post activation (p.a.)

188 with the different AM were plotted. Storage time of sperm $(\leq 22 \mathrm{~h})$ did not significantly

189 affect the percent sperm motile as a covariate after sperm activation in $100 \mathrm{SW}$

190 (intercept: $P>0.05, \mathrm{~F}=2.36, \mathrm{df}=5$; slope: $P>0.05 ; \mathrm{F}=1.75 ; \mathrm{df}=3 ;$ ANCOVA).

191 Only sperm with storage time of $10 \mathrm{~h}$ were kept for sperm activation in $50 \mathrm{SW}$. Sperm

192 samples activated in 10 OF were all tested $10 \mathrm{~h}$ after gamete collection. Therefore, for

193 evaluating the percent sperm motile as a function of the time p.a., data collected from

194 sperm samples with storage periods lower than $30 \mathrm{~h}$ were used for activation in $100 \mathrm{SW}$

195 and with storage periods of $10 \mathrm{~h}$ for sperm activation in $50 \mathrm{SW}$ and $10 \mathrm{OF}$. 


\subsubsection{Sperm storage at $4^{\circ} \mathrm{C}$}

As soon as sperm samples were brought back to the laboratories (Høyteknologisenteret, HIB, Bergen, Norway and Ifremer Brest, France) they were stored in refrigerators at $4{ }^{\circ} \mathrm{C}$. The effect of storage at $4^{\circ} \mathrm{C}$ on percent sperm motile was assessed on sperm samples activated by dilution in $100 \mathrm{SW}$. These measurements were performed approximately every $24 \mathrm{~h}$ after stripping until the sperm sample did not show any cell movement. To plot percent sperm motile versus sperm storage period at $4{ }^{\circ} \mathrm{C}$, only the percent sperm motile recorded at $15 \mathrm{~s}$ after activation were considered. The sperm storage period was calculated as the time between stripping and assessment of sperm motility. The storage suitability at $4^{\circ} \mathrm{C}$ of a sperm sample was defined as the storage period at which $10 \%$ of spermatozoa were still motile.

\subsubsection{Cryopreservation}

The time period between sperm stripping and cryopreservation was calculated for each sperm sample $(n=1 \mathrm{Nw}+21 \mathrm{Fr})$ and ranged from 21 to $54 \mathrm{~h}$. Hake sperm samples were frozen after dilution (1:2) in Mounib's Modified Medium extender, supplemented with $10 \%$ BSA and $10 \%$ of dimethyl sulfoxide DMSO (Sigma -Aldrich Inc., Sigma ref D2438, St-Louis, MO 63103, USA) used as a cryoprotectant according to the method of Dreanno et al. (1997) used for turbot (Psetta maxima). This protocol used for turbot was also shown to be successful for cryopreserving sea bass sperm (Fauvel et al., 1998). Hake sperm samples (one volume) were mixed with freezing extender (two volumes), corresponding to a final DMSO concentration of $0.94 \mathrm{M}$. No equilibration time was allowed. The diluted sperm sample was back aspirated into $\mathrm{CBS}^{\mathrm{TM}} 0.3 \mathrm{ml}$ straws (Cryo Bio System, I.M.V. Technologies Group, L’Aigle, France) using a micropipette (in triplicate for each male) and immediately sealed with the 
222 SYMS sealing system (Cryo Bio System, I.M.V. Technologies Group, L’Aigle, France).

223 Freezing was achieved using a polystyrene box covered with a lid (external 224 measurements $\mathrm{L} \times \mathrm{W} \times \mathrm{H}=33 \times 25 \times 30 \mathrm{~cm}$ ), half filled with liquid nitrogen (LN). The 225 straws were placed inside and floated in nitrogen vapour, $6.5 \mathrm{~cm}$ above the surface, on a 226 raft (Styrofoam and plastic grid). After $15 \mathrm{~min}$ (temperature of the straws decreased 227 from 21 to $-60^{\circ} \mathrm{C}$; unpublished data), straws were deep plunged into $\mathrm{LN}\left(-196^{\circ} \mathrm{C}\right)$ and 228 stored submerged until thawing. For thawing, straws were immersed for five seconds in 229 a $35^{\circ} \mathrm{C}$ water bath. After drying, straws were cut open to carefully release the volume 230 into an Eppendorf tube. Separate $2.5 \mu 1$ aliquots of this frozen-thawed sperm were then 231 immediately activated with $397.5 \mu l$ of $100 \mathrm{SW}$.

\subsection{Data analyses}

Statistical analyses were performed using the software SigmaStat 3.1. Data were presented as means \pm SD. Significant differences in sperm characteristics between

236 Norwegian and French samples were examined using a Student's t-test when data were 237 distributed normally and variances were not significantly different or a Mann-Whitney Rank Sum test if one of these two previous conditions or both were invalid. No significant size effect (TL) on sperm characteristics was found $(P>0.05 ; \mathrm{t}$-test),

240 therefore analyses could be conducted on all sizes pooled. Relationships between sperm

241 production indices and characteristics of individual fish were investigated with Pearson correlations for Norwegian and French samples, separately.

244 sperm motility analyses. Percent sperm motile were regressed on time p.a. The

245 coefficient of determination $\left(\mathrm{R}^{2}\right)$ calculated by ordinary least-squares regression, 246 allowed us to define the regression line approximating at best the real data points (i.e. 
247 the regression with the highest $\mathrm{R}^{2}$ was selected). The effect of $100 \mathrm{SW}$ was tested on 248 both $\mathrm{Nw}$ and Fr sperm samples (50 SW and $10 \mathrm{OF}$ were tested only on Nw-sperm 249 samples). ANCOVA with interaction and Ln time transformed data were used to 250 compare regressions fitted separately to $\mathrm{Nw}$ and Fr data: since no significant difference 251 was observed in motility after activation (intercept: $P>0.05, \mathrm{~F}=3.50$, $\mathrm{df}=1$; slope: $252 P>0.05 ; \mathrm{F}=1.58 ; \mathrm{df}=1 ;$ ANCOVA), a general regression was fitted to the pooled 253 data of both groups ( $\mathrm{Nw}$ and Fr samples). Data were Ln transformed to satisfy the homogeneity of variances assumption for the errors and to linearize the fit as much as possible.

The origin of sperm samples as well as the storage times between collection and first measurements for Nw and Fr samples were not significantly different $(P>0.05$, Mann-Whitney Rank Sum Test). Changes in percent sperm motile as a function of sperm storage period at $4^{\circ} \mathrm{C}$ for sperm activated with $100 \mathrm{SW}$ were compared between Nw and Fr samples at $15 \mathrm{~s}$ p.a. Because no significant differences were observed between both groups (intercept: $P>0.05, \mathrm{~F}=0.02$, $\mathrm{df}=1$; slope: $P>0.05 ; \mathrm{F}=1.06$; $\mathrm{df}=1$; ANCOVA) a general regression was fitted to the pooled data and the regression with the highest $\mathrm{R}^{2}$ selected.

A repeated measures ANOVA was conducted to test the difference between percent of fresh compared to thawed sperm. Normality and equal variance were not achieved. Therefore, the motility data (\%) were arcsine transformed data prior to analysis using the following formula: ASIN $x\{\sqrt{ }($ percent sperm motile $/ 100)\}$. A mean motility recovery index was calculated: motility recovery index $=(\%$ motility thawed sperm / \% motility fresh sperm) $* 100$.

\section{Results}




\subsection{Fish and sperm production characteristics}

The Norwegian hake were significantly longer, heavier, and had a higher reproductive investment (GSI) compared to French hake (Table 1). GSIs estimated for Nw-hake caught from mid-August until mid-September varied around $4.8 \%$ (with a decline from 7.5 to $2.9 \%$ ) while GSIs estimated on Fr-hake caught at the end of March, early April were stable at $\sim 1.1 \%$ (Table 1 ). Spermatozoa concentration was twice as high in the samples from Fr compared to Nw-fish samples (Table 1). Sperm production indices from $\mathrm{Nw}$ and Fr-stripped hake were estimated and showed high variations for all variables except for $\mathrm{pH}$ (Table 1).

\subsection{Fish characteristics vs sperm production indices}

No significant correlations were observed between TL, TW, K or HSI and any of the sperm characteristics. Likewise, no significant correlation was observed between Nwspermatocrit and $\mathrm{Nw}$-spermatozoa concentration while a significant positive correlation was observed between Fr-spermatocrit and Fr-spermatozoa concentration $(r=0.539$, $\mathrm{n}=18 ; \quad P<0.05)$. A significant positive correlation was observed between Frspermatozoa concentration and Fr-GSI $(\mathrm{r}=0.831, \mathrm{n}=6 ; P<0.05)$. A significant negative correlation appeared between Fr-osmolality and Fr-pH $(r=-0.786, n=9$; $P<0.05)$

\subsection{Measurement of sperm motility characteristics}

\subsubsection{Sperm motility versus time post activation}

Activation by transfer into $100 \mathrm{SW}$ or $10 \mathrm{OF}$ occurred synchronously for virtually all spermatozoa. The percent sperm motile (y) was highest immediately after activation, and then declined with time p.a. (x) (Fig. 1). Significant correlations were 
297 observed between percent sperm motile and time p.a. when sperm were activated with $298100 \mathrm{SW}: \mathrm{y}=-26.5 \mathrm{Ln}(\mathrm{x})+162.7 ; \mathrm{R}^{2}=0.875 ; P<0.001$ and when sperm were activated

299 with 10 OF: $y=-0.09 x+81.91 ; \mathrm{R}^{2}=0.873 ; P<0.001$. In contrast, following activation 300 with $50 \mathrm{SW}$ only a few spermatozoa were activated immediately, with maximum 301 percent sperm motile being attained at $608 \pm 174 \mathrm{~s}$ p.a., after which the percentage of

302 motile cells again gradually declined over time (Fig. 1). A significant correlation was 303 observed between percent sperm motile and time p.a. when sperm were activated with $50 \mathrm{SW}: \mathrm{y}=-2 \exp \left(-05 \mathrm{x}^{2}\right)+0.030 \mathrm{x}+27.02 ; \mathrm{R}^{2}=0.213 ; P<0.01$ Taken together, there were clear differences in the decrease of motile sperm depending upon whether sperm samples were activated with $50 \mathrm{SW}, 10 \mathrm{OF}$ or $100 \mathrm{SW}$

307 (Fig. 1): spermatozoa showed longer total motility durations when activated with 50 SW $308(1570 \pm 295 \mathrm{~s})$ or $10 \mathrm{OF}(718 \pm 71 \mathrm{~s})$ compared to activation by $100 \mathrm{SW}(317 \pm 121 \mathrm{~s})$. 309 According to our regressions, the time p.a. at which $50 \%$ of motility is reached was 310 more than five times longer when sperm were activated with $10 \mathrm{OF}$ ( $355 \mathrm{~s})$ than when 311 sperm were activated with $100 \mathrm{SW}(70 \mathrm{~s})$.

\subsubsection{Sperm storage at $4^{\circ} \mathrm{C}$}

The percentage of motility observed when sperm were transferred into $100 \mathrm{SW}$

315 decreased with sperm storage period (Fig. 2). Undiluted sperm could be stored at $4{ }^{\circ} \mathrm{C}$ 316 for 10 days $(237 \mathrm{~h})$ and still retain $10 \%$ of motility. According to our observations, after 3172 days $(48 \mathrm{~h})$ at $4^{\circ} \mathrm{C}$ the percent sperm motile ranged from 0 to $90 \%$. After 318 approximately 9 days $(220 \mathrm{~h})$, percent sperm motile values of 50 and $65 \%$ were still 319 observed in two individuals. The decrease in percent sperm motile with storage period 320 varied highly among individuals. 
322

323

324

325

326

327

328

329

330

331

332

333

334

335

336

337

338

340

341

342

343

344

345 In comparison to other marine species, the sperm volume found in this study (3.9 and 346

\subsubsection{Cryopreservation}

For every sperm sample tested, fresh sperm always showed higher motility percentages compared to thawed sperm. However, for 4 out of 22 sperm samples ( $1 \mathrm{Nw}$ and $3 \mathrm{Fr}$ ) the effect of cryopreservation on sperm motility was not significant $(P>0.05$, repeated measures ANOVA). Hake sperm showed a mean motility recovery index of $15.6 \pm 17.0 \%$ for Fr-sperm samples $(\mathrm{n}=21)$ and the only Nw-sample tested showed a motility recovery index of $76.4 \%$.

\section{Discussion}

Basic biological features of European hake sperm are presented in this study. It was necessary to collect hake sperm samples from wild individuals because no hake spawning broodstock was available at the time of the study. The Fr-sampling was carried out in March - April which was late in the season according to Lucio et al. (2000) who found the peak spawning season for hake spanning from February to March in the Bay of Biscay. The Fr-hake collected in the present study showed low GSI (from 0.95 to $1.24 \%$ ), and probably reflects the fact that these males were sampled towards the end of their spawning season, concomitant with a decrease in testes weight. These males had most likely completed most of their spawning activity, and as a result their testes only contained residual sperm. In contrast, higher GSI values were observed in Nw-hake (7.5\%), indicating fully mature individuals at the beginning of their spawning season.

\subsection{Hake sperm production indices} $2.6 \mathrm{ml}$ respectively in $\mathrm{Nw}$ and Fr samples) was low compared to cod (Gadus morhua) 
347 (Tuset et al., 2008) and high compared to turbot (0.2 ml, Chauvaud et al., 1995).

348 Similarly, spermatozoa concentration and total number of spermatozoa recorded for

349 hake were lower than values observed in cod (Trippel, 2003; Stockley et al., 1997) but

350 higher than values found in turbot $\left(0.7\right.$ to $11 \times 10^{9}$ spermatozoa $/ \mathrm{ml}$, Chauvaud et al., 351 1995). Hake exhibited spermatocrit values close to those reported in cod (Trippel, 352 2003). The somewhat thicker sperm in Fr-samples is consistent with the fact that Fr353 sperm were collected at the end of the spawning season (Rakitin et al., 1999). The 354 average osmolality calculated for Fr-hake sperm samples $(349 \pm 28 \mathrm{mOsmol} / \mathrm{kg})$ was 355 close to values reported previously in cod (360 - $380 \mathrm{mOsmol} / \mathrm{kg})$ by Hwang and Idler 356 (1969) and Litvak and Trippel (1998) as well as Rouxel et al. (2008) (332 $357407 \mathrm{mOsmol} / \mathrm{kg}$ ). The seminal fluid $\mathrm{pH}$ measured in Fr-hake sperm samples (pH 7.6) 358 was lower than values measured in cod $(\mathrm{pH} 7.9$ - 8.4; Hwang and Idler, 1969; Litvak 359 and Trippel, 1998; Rouxel et al., 2008). Hence, sperm production of hake was lower 360 than cod and higher than turbot.

361 The significant relationship found between Fr-spermatocrit and Fr-spermatozoa

362 concentration suggests the potential utility of spermatocrit as a simple and rapid 363 estimator of spermatozoa concentration in Fr-hake. However, this result needs more

364 investigation as this relationship was not apparent for the Nw-data in the present study.

365 These types of relationships have previously been reported in cod (Rakitin et al., 1999) 366 and in haddock (Melanogrammus aeglefinus) (Rideout et al., 2004).

\subsection{Hake sperm motility}

369 When activated with $100 \mathrm{SW}$ at room temperature $\left(22^{\circ} \mathrm{C}\right)$, all hake spermatozoa ceased

370 any activity after $465 \mathrm{~s}$. Under similar recording conditions the duration of sperm 371 motility in cod is $700-800 \mathrm{~s}$ (Cosson et al., 2008a). Furthermore, the percent sperm 
372 motility of hake declined by $50 \%$ at 70 s post activation. In cod, $95 \%$ of the cells were

373 still motile after $50 \mathrm{~s}$ (Cosson et al., 2008b). When hake sperm were activated with

$374100 \mathrm{SW}$ or $50 \mathrm{SW}$, it was shown that total motility duration is inversely related to AM

375 osmolality. This observation is supported by earlier findings of Billard (1978) and

376 Lahnsteiner and Patzner (1998), who showed durations of sperm motility in a number of

377 marine species were longer in partly diluted sea water compared to full-strength sea

378 water, probably because it leads to a less harmful osmotic environment for sperm

379 (extreme osmotic situations could provoke local membrane distortions leading to

380 flagellar blebs or coils) (Cosson et al., 2008c). When activated with $10 \mathrm{OF}$, spermatozoa

381 also showed a longer total motility duration compared to $100 \mathrm{SW}$. The presence of OF

382 in the spawning medium can have significant positive effect on teleost spermatozoa

383 motility and fertility (Litvak and Trippel, 1998; Elofsson et al., 2003). By prolonging

384 gamete contact times during the fertilization process one may significantly increase egg

385 fertilization success as suggested by Butts et al. (2009). The implications of these

386 findings are relevant to aquaculture practices. "Wet fertilization" is commonly practiced

387 for many marine species as it allows the mixing of sperm first with an AM, thus

388 avoiding having to pour sperm on eggs within seconds (Trippel and Morgan, 1994).

\subsection{Sperm storage}

391 Hake sperm viability was maintained for 10 days at $4^{\circ} \mathrm{C}$. These results were comparable

392 to observations in cod sperm by De Graaf and Berlinsky (2004), where undiluted sperm 393 stored at $4^{\circ} \mathrm{C}$ still showed $11.0 \pm 0.7 \%$ of motile cells after 10 days. However, after $48 \mathrm{~h}$ 394 at $4^{\circ} \mathrm{C}$ the percent sperm motile for hake ranged from 0 to $90 \%$. Sperm samples 395 showing less than $40 \%$ motility after $48 \mathrm{~h}$ at $4^{\circ} \mathrm{C}$ all originated from France. Rouxel et 396 al. (2008) observed higher storage potential of cod sperm when collected during the 
397 mid-period of the spawning season, as compared to sperm collected at the beginning or

398 end of the spawning season. Our French data corroborate this finding: a low storage

399 potential was highlighted for the sperm collected at the end of the spawning period (Fr-

400 hake).

401 Generally, DMSO is the most commonly used and most successful cryoprotectant for

402 sperm cryopreservation of marine fish (Leung and Jamieson, 1991; Stoss, 1983; Suquet 403 et al., 2000). The effect of DMSO is concentration dependent, with a concentration 404 between 5 and $20 \%$ commonly used (Suquet et al., 2000). In agreement with this, our 405 results showed that DMSO at $10 \%$ could be used as cryoprotectant for hake sperm. The 406 techniques established by Dreanno et al. (1997) for turbot sperm cryopreservation 407 appear to be suitable for European hake, as the mean motility recovery index for Fr408 samples was $15.6 \pm 17.0 \%$ and the motility recovery index for the Nw-sample was $40976.4 \%$. The mean value for Fr-samples was low compared to the results found in cod 410 by De Graaf and Berlinsky (2004) who achieved a motility recovery index of $41166.0 \pm 2.1 \%$. However, the motility recovery index appears to be related to the time of 412 sperm collection. For example, according to Rideout et al. (2004), cod sperm collected 413 at the end of the spawning season showed a reduced post-thaw motility compared with 414 those collected two weeks after the earliest part of the spawning season. In conclusion, this study provides original data on European hake sperm quality 417 which should be beneficial for the future development of any aquaculture program of 418 this species.

\section{Acknowledgements}


421 Authors would in particular like to thank fishermen for welcoming us on board to 422 collect the biological material. Technical help in collecting the biological material on 423 different cruises was provided by Julie Skadal, Vibeke Lokøy, Frank Midtøy, Otte 424 Bjelland, François Garren and Stéphane Martin and greatly appreciated. Our thanks also 425 go to Trygve Nilsen for statistical advice and to Paolo Simonelli for help with sperm 426 motility assessment. Financial supports were provided through the European Union 427 IBACS Q5RS-2002-01610), the Norwegian Research Council (NFR, Aurora 428 Programme) and the Department of Biology at the University of Bergen (UiB). 429 Constructive criticisms and comments of four anonymous reviewers were greatly 430 appreciated.

\section{References}

433 Belloc, G., 1935. Etude monographique du merlu Merluccius merluccius L., 3ème 434 partie. Revue des Travaux de l'Office des Pêches Maritimes 8, 145-202.

436 Billard, R., 1978. Changes in structure and fertilizing ability of marine and fresh water 437 fish spermatozoa diluted with media of various salinities. Aquaculture 14, 187-198.

439 Billard, R. Cosson, M. P., 1992. Some problems related to the assessment of sperm 440 motility in fresh-water fish. J. Exp. Zool. 261(2), 122-131.

442 Billard, R., Cosson, J., Perchec, G., Linhart, O. 1995. Biology of sperm and artificial 443 reproduction in carp. Aquaculture 129, 95-112. 
445 Bjelland, R.M., Skiftesvik, A.B., 2006. Larval development in European hake

446 (Merluccius merluccius L.) reared in a semi-intensive culture system. Aquac. Res. 37, $447 \quad 1117-1129$.

448

449 Butts, I.A.E., Trippel, E.A., Litvak, M.K., 2009. The effect of sperm to egg ratio and 450 gamete contact time on fertilization success in Atlantic cod Gadus morhua L. 451 Aquaculture 286, 89-94.

452

453 Casey, J., Pereiro, J.A., 1995. European hake (M. merluccius) in the North-east Atlantic. 454 In: Hake: fisheries and markets. Alheit J. \& Pitcher T.J. (Eds.). Chapman \& Hall, 455 London, pp. 125-147.

456

457 Chauvaud, L., Cosson, J., Suquet, M., Billard, R., 1995. Sperm motility in turbot, 458 Scophthalmus maximus - Initiation of movement and changes with time of swimming 459 characteristics. Environmental Biology of Fishes 43(4), 341-349.

460

461 Cosson, J., Huitorel, P., Gagnon, C., 2003. How spermatozoa come to be confined to 462 surfaces. Cell Mot. \& Cytoskel. 54(1), 56-63 (12).

463

464 Cosson, J., Groison, A.L., Suquet, M., Fauvel, C., 2008a. Motility characteristics of 465 spermatozoa in cod (Gadus morhua) and hake (Merluccius merluccius). Cybium 32 (2), $466 \quad 176-177$. 
468 Cosson, J., Groison, A.L., Suquet, M., Fauvel, C., Dreanno, C., Billard, R., 2008 b.

469 Studying sperm motility in marine fish: an overview on the state of the art. J. Appl. $470 \quad$ Ichthyol. 24, 460-486.

471

472 Cosson, J., Groison, A.L., Suquet, M., Fauvel, C., Dreanno, C., Billard, R., 2008c.

473 Marine fish spermatozoa: racing ephermal swimmers. Reproduction 136, 277-294.

474

475 De Graaf, J.D., Berlinsky, D.L., 2004. Cryogenic and refridgerated storage of Atlantic 476 cod (Gadus morhua) and haddock (Melanogrammus aeglefinus) spermatozoa. 477 Aquaculture 234, 527-540.

478

479 Dreanno, C., Suquet, M., Quémener, L., Cosson, J., Fierville, F., Normand, Y., Billard, 480 R., 1997. Cryopreservation of turbot (Scophthalmus maximus) sperm. Theriogenology $48148,589-603$.

482

483 Elofsson, H., McAllister, B., Kime, D., Mayer, I., Borg, B., 2003. Long lasting sperm in 484 sticklebacks; ovarian fluid a key to success in freshwater? J. Fish Biol. 63, 240-253.

485

486 Engelsen, R., Asche, F., Skjennum, F., Adoff, G., 2004. New species in aquaculture: 487 some basic economic aspects. In: Culture of cold-water marine fish. Moksness, E.; 488 Kjørsvik, E., Olsen, Y. (Ed.). Blackwell Publishing, Oxford, UK, pp. 487-515

489

490 FAO yearbook, 2006. Fishery statistics: capture production 2004. 98/1, 560 pp. 491 
492 Fauvel, C., Suquet, M., Dreanno, C., Zonno, V., Menu, B., 1998. Cryopreservation of

493

494

495

496

497

498

499

500

501

502

503

504

505

506

507

508

509

510

511

512 Leung, L.K.P., Jamieson B.G.M., 1991. Live preservation of fish gametes. In: Jamieson

513 B.G.M., Editor, Fish Evolution and Systematics: Evidence from Spermatozoa,

514 Cambridge University Press, Cambridge, pp. 245-269. 
516 Litvak, M.K., Trippel, E.A., 1998. Sperm motility patterns of Atlantic cod (Gadus

517 morhua) in relation to salinity: effects of ovarian fluid and egg presence. Can. J. Fish.

518 Aqua. Sci. 55 (8), 1871-1877.

519

520 Lucio, P., Murua, H., Santurtún, M., 2000. Growth and reproduction of hake 521 (Merluccius merluccius) in the Bay of Biscay during the period 1996-1997. 522 Ozeanografika 3, 325-354.

523

524 Medina, A., Megina, C., Abascal, F.J., Calzada, A., 2003. The sperm ultrastructure of 525 Merluccius merluccius (Teleostei, Gadiformes): phylogenetic considerations. Acta 526 Zool. (Stockholm) 84, 131-137.

527

528 Murua, H., Motos, L., 2006. Reproductive strategy and spawning activity of the 529 European hake Merluccius merluccius (L.) in the Bay of Biscay. J. Fish Biol. 69, 12885301303.

531

532 Quémener, L., Suquet, M., Mero, D., Gaignon, J.L., 2002. Selection method of new 533 candidates for finfish aquaculture: the case of the French Atlantic, the Channel and the

534 North Sea coasts. Aqua. Liv. Res. 15 (5), 293-302.

535

536 Rakitin, A., Ferguson, M.M., Trippel, E.A., 1999. Spermatocrit and spermatozoa 537 density in Atlantic cod (Gadus morhua): correlation and variation during the spawning 538 season. Aquaculture 170, 349-358.

539 
540 Rideout, R.M., Trippel, E.A., Litvak, M.K., 2004. The development of haddock and

541 Atlantic cod sperm cryopreservation techniques and the effect of sperm age on

542 cryopreservation success. J. Fish Biol. 65, 299-311.

543

544 Rouxel, C., Suquet, M., Cosson, J., Severe, A., Quémener, L., Fauvel, C., 2008.

545 Changes in Atlantic cod (Gadus morhua L.) sperm quality during the spawning season.

546 Aquac. Res. 39, 434-440.

547

548 Stockley, P., Gage, M.J.G., Parker, G.A., Moller, A.P., 1997. Sperm competition in

549 fishes: the evolution of testis size and ejaculate characteristics. American Naturalist $550 \quad 149(5), 933-954$.

551

552 Stoss, J., 1983. Fish gamete preservation and spermatozoan physiology. In: Donaldson, 553 E.M., Hoar, W.S.

Suquet, M., Dreanno, C., Fauvel, C., Cosson, J., Billard, R., 2000. Cryopreservation of 556 sperm in marine fish, Aquac. Res. 31, 231-243.

557

558 Trippel, E.A., 2003. Estimation of male reproductive success of marine fishes. J. 559 Northw. Atl. Fish. Sci. 33, 81-113.

561 Trippel, E.A, Morgan, M.J., 1994. Age-specific paternal influences on reproductive success of Atlantic cod (Gadus morhua L.) of the Grand Banks, Newfoundland. ICES Mar. Sci. Symp. 198, 414-422. 
565 Tuset, V.M., Trippel, E.A., de Monserrat, J., 2008. Sperm morphology and its influence 566 on swimming speed in Atlantic cod. J. Appl. Ichthyol. 24, 398-405. 
568 Table 1. Fish and sperm characteristics of European hake from two areas:

569 Statistically significant differences between Norwegian (Nw) and French (Fr) samples

570 are indicated with $* \mathrm{P}<0.05, * * \mathrm{P}<0.01$, and $* * * \mathrm{P}<0.001$. Osmolality and $\mathrm{pH}$ were

571 measured for sperm samples from Fr-hake only. GSI values are presented by date of

572 collection.

\begin{tabular}{|c|c|c|c|c|c|c|}
\hline \multicolumn{2}{|l|}{ Variables } & Origin & $\boldsymbol{N}$ & Mean & S.D. & Significance \\
\hline \multicolumn{7}{|c|}{ Sampled fish characteristics } \\
\hline \multirow{2}{*}{\multicolumn{2}{|c|}{ TL $(\mathrm{cm})$}} & $\mathbf{N w}$ & 19 & 68.5 & 8.5 & *** \\
\hline & & Fr & 42 & 40.1 & 9.5 & \\
\hline \multirow{2}{*}{\multicolumn{2}{|c|}{ TW (cm) }} & $\mathbf{N w}$ & 16 & 2498 & 822 & $* * *$ \\
\hline & & $\mathbf{F r}$ & 42 & 490 & 351 & \\
\hline \multirow{2}{*}{\multicolumn{2}{|c|}{$\underline{\mathbf{K}}$}} & $\mathbf{N w}$ & 16 & 0.69 & 0.05 & n.s \\
\hline & & $\mathbf{F r}$ & 42 & 1.24 & 3.98 & \\
\hline \multirow[t]{8}{*}{ GSI (\%) } & collection date & $\mathbf{N w}$ & 10 & 4.80 & 2.94 & \\
\hline & 17.08 .05 & & & 7.52 & 2.28 & \\
\hline & 22.08 .06 & & & 5.31 & & \\
\hline & 01.09 .05 & & & 4.35 & 3.40 & $* * *$ \\
\hline & 12-14.09.06 & & & 2.94 & 1.87 & \\
\hline & & $\mathbf{F r}$ & 18 & 1.10 & 0.51 & \\
\hline & $20-21.03 .06$ & & & 1.24 & 0.55 & \\
\hline & 04-05.04.06 & & & 0.95 & 0.44 & \\
\hline \multirow{2}{*}{\multicolumn{2}{|c|}{ HSI (\%) }} & $\mathbf{N w}$ & 16 & 2.62 & 1.04 & n.s \\
\hline & & $\mathbf{F r}$ & 17 & 1.89 & 0.93 & \\
\hline \multicolumn{7}{|c|}{ Sperm production indices } \\
\hline \multirow{2}{*}{\multicolumn{2}{|c|}{ Sperm volume (ml) }} & $\mathbf{N w}$ & 19 & 3.9 & 4.0 & n.s \\
\hline & & Fr & 45 & 2.6 & 4.0 & \\
\hline \multirow{2}{*}{\multicolumn{2}{|c|}{ Spz conc $\left(x 10^{9} \mathrm{spz} / \mathrm{ml}\right)$}} & Nw & 5 & 6.6 & 3.2 & ** \\
\hline & & $\mathbf{F r}$ & 29 & 13.9 & 5.1 & \\
\hline \multirow{2}{*}{\multicolumn{2}{|c|}{ Spermatocrit(\%) }} & $\mathbf{N w}$ & 5 & 80.2 & 3.3 & n.s \\
\hline & & Fr & 19 & 81.8 & 10.7 & \\
\hline \multirow{2}{*}{\multicolumn{2}{|c|}{ Tot no of spermatozoa ( $\left.\times 10^{9} \mathrm{spz}\right)$}} & $\mathbf{N w}$ & 5 & 23.5 & 30.0 & n.s \\
\hline & & Fr & 29 & 35.1 & 36.2 & \\
\hline \multicolumn{2}{|c|}{ Osmolality (mOsmol/ kg) } & $\mathbf{F r}$ & 13 & 349 & 28 & \\
\hline \multicolumn{2}{|l|}{$\mathrm{pH}$} & Fr & 9 & 7.6 & 0.1 & \\
\hline
\end{tabular}


$574 \quad$ Figures legends

575 Fig. 1. Changes in the percent sperm motile with time post activation of European hake:

576 Sperm stored for periods $\leq 22 \mathrm{~h}$ were activated by dilution in $100 \%$ sea water (100 SW)

577 (plain black signs and black regression line) $(N=3$ Norwegian hake +11 French hake), $57850 \% \mathrm{SW}$ diluted with distilled water (50 SW) (cross and dashed regression line)

$579(N=2$ Norwegian hake) or $10 \%$ ovarian fluid in SW (10 OF) (plain grey signs and grey 580 regression line) $(N=2$ Norwegian hake).

581

582 Fig. 2. Changes in percent sperm motile of European hake with duration of sperm

583 storage at $4^{\circ} \mathrm{C}$. Sperm $(N=5$ Norwegian hake +29 French hake $)$ were activated with $584100 \%$ sea water (100 SW). A regression was fitted to the entire data set:

585

$$
\mathrm{y}=-23.9 \operatorname{Ln}(\mathrm{x})+139.8 ; \mathrm{R}^{2}=0.426 ; P<0.001
$$


$587 \quad$ Figures

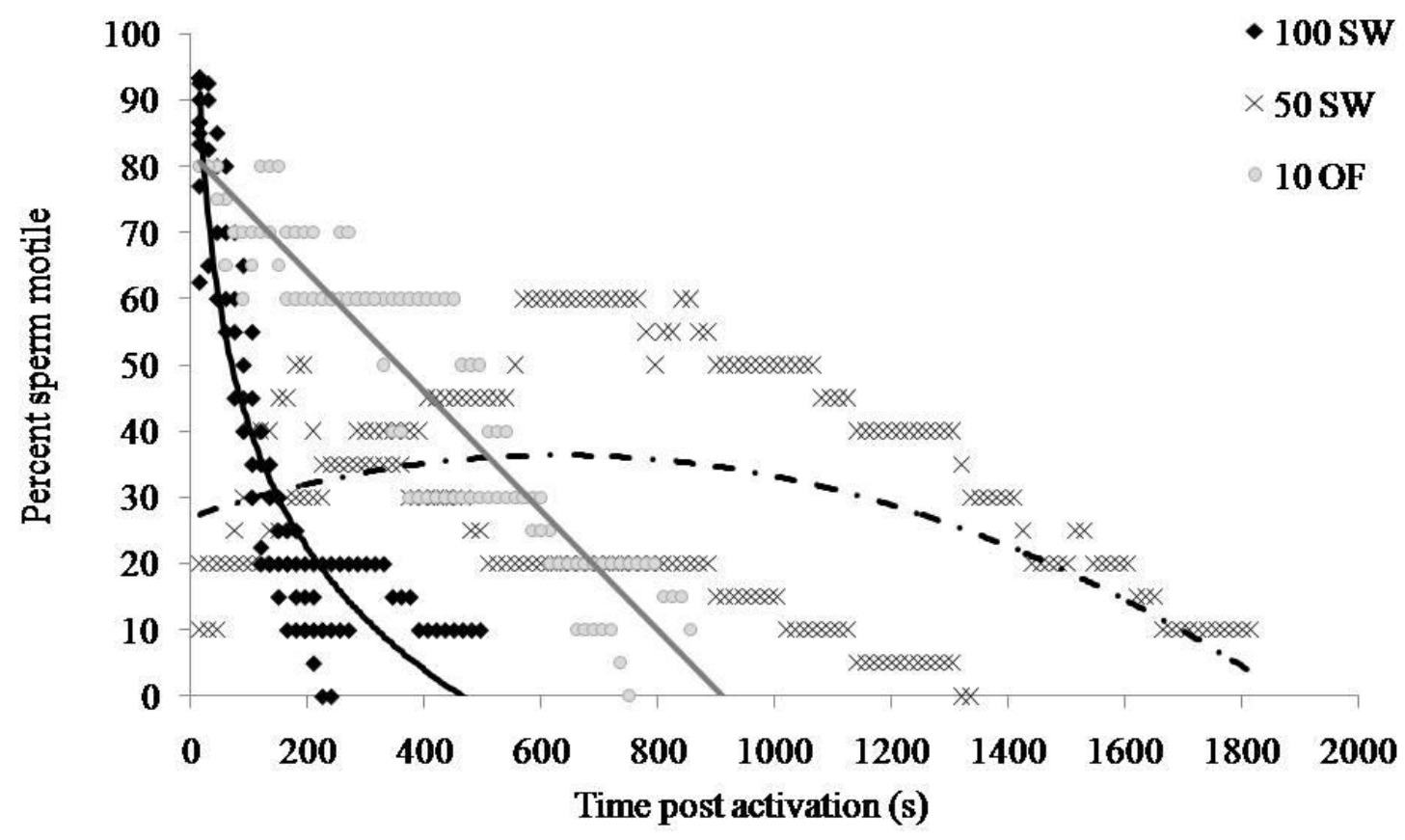

588

589 Fig. 1.

590

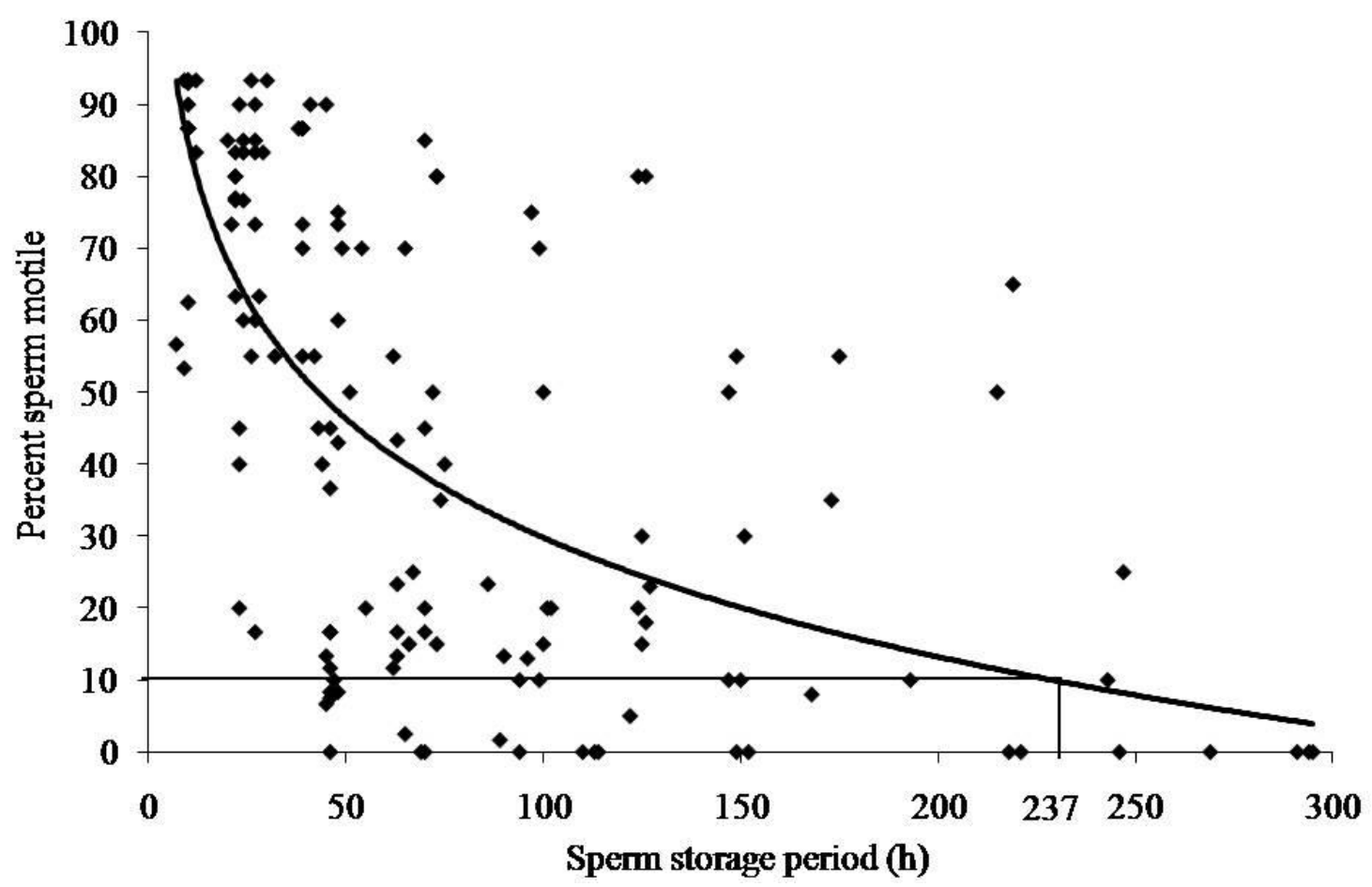

591

592 Fig. 2. 